\title{
The Textual and Cultural Features in High-quality Translation of Literary Prose
}

\author{
Xinyi Gao \\ University College London
}

\begin{abstract}
The quality of translation has been paid more attention in recent years, especially that of literary prose. The author aims to analyze the importance of textual and cultural features in high-quality translation of literary prose by using text typology theory and skopos theory. The author's own revised translation of Eileen Chang's literary prose is cited as an example in this essay.
\end{abstract}

Keywords: Textual and cultural feature, Translation, Literary prose, Eileen Chang.

\section{Introduction}

There is no doubt that the quality of translations has become increasingly more important. With the advancement of globalization, the roles and duties of translators have greatly changed as the skills a translator need are not simply restricted to language or linguistic competences, but should be balanced with broad general knowledge and understanding of culture. Meanwhile, the translators must have a good grasp of the subject matter or text type they are translating. Thus, the combination of different skills consolidates the translation quality greatly and only with high-quality translation, the smooth interaction between people and cultures in the modern world can be carried on.

When it comes to the production of high-quality translations, the author contends that the translators should fully take cultural and textual features of the source text into account. Compared with translation studies of other literary genres, prose is a quite general concept appearing in different forms of writing, the researches of which are relatively few. Thus, the author wants to give a full explanation through the analysis of the translation of a representative lyric prose, “到底是上海 人" from Eileen Chang, a famous Chinese writer who is especially skilled in adopting metaphors and parallel constructions to pass on cultures, traditions, and values. In this prose, she describes Shanghainese's characters and quotes some verses, common sayings, and Chinese slangs. Through the analysis, the author tries to compare the two features in order to improve the translation quality and achieve the criteria raised by Yan.

\section{Theoretical Framework}

In Text Typology and Translation, Trosborg (1997) breaks new ground in translation theory and practice and analyses the ways translations are affected by text types [1]. Meanwhile, to achieve faithfulness of the translation, the skopos for translating the work should also be considered to convince the readers and to achieve elegance, the translated prose should fit into the target culture, from which the significance of textual and cultural features is embodied. The most distinctive theories in this field are Katharina Reiss's text typology theory, Hans Vermeer's skopos theory and cultural turn.
Katharina Reiss (2000) raised text typology theory in her book, Translation criticism: The potentials and limitations [2]. She claimed that the research on the translation should vary according to different text types in accordance with Karl Bühler's model on language functions. Quite a few scholars had proposed theories in terms of language functions and text typologies before the 1970s, which had exerted great influences on Reiss's works. Reiss went a step further as she developed Bühler's ideas and divided text typology into three main categories, containing the content-focused text, the form-focused text, as well as the appeal-focused text. Reiss's theories were summarized by Jeremy Munday (2001) in Introducing Translation Studies: Theories and Applications [3].

In the development of functionalist approaches to translation, Skopos theory put forward by Hans Vermeer in 1978 has played a major role. It is an approach to translation that was developed in Germany, which reflects a general shift from predominantly linguistic and rather formal translation theories to a more functionally and socioculturally oriented concept of translation. The translation is considered not as a process of translation, but as a specific form of human action. Vermeer (2014) further developed the theory in his co-authored book Towards a General Theory of Translational Action [4]. The skopos theory holds that the way the target text eventually shapes up is determined to a great extent by the function or "skopos" (Hatim and Munday, 2004) [5]. Translation, therefore, has a purpose, and the word "skopos" was from Greek, which is used as the technical term for the "purpose" of the translation. The skopos theory takes seriously factors including the culture of the intended readers of the target text and of the client who has commissioned it, and, in particular, the function which the text is to perform in that culture for those readers. It should function well in the target culture and circumstances as everything will depend on how people want to use it. The role of textual feature has become more vital than before.

During the development and innovation of different translation theories, the definition of cultural turn also grew up. Homes (1972) stressed in The Cross-Temporal Factor in Verse Translation that poetry changed constantly, and the 
translators should think about the different cultural elements of different ages [6]. Later, Snell Hornby (1995) thought that translation is a cross-cultural activity in her book Translation Studies: An Integrated Approach and emphasized that language is a part of the culture and the relatedness of language and culture [7]. Hornby introduced Reiss's theory of text type and Vermeer's Skopos theory as she believed that their theories changed the direction of research from linguistic transfer to cultural transfer, which focused on the orientation towards cultural rather than linguistic transfer, took translation as a communicative behavior rather than a transcoding process, and see a close relationship between the text and the outside world.

From the above analysis, it is not hard to see that the focus has been changed gradually from the simple linguistic feature. Therefore, the above theories will be used in the analysis of textual and cultural features in high-quality translation of lyric proses.

\section{Textual Features in High-Quality Translation of Lyric Prose}

To begin with, the textual feature is of great importance in producing high-quality translation of lyric prose as the text typology decides the translation strategy.

According to Reiss's text typology theory, she proposed that form-focused texts are texts based on formal literary principles, and texts which express more than they state, where figures of speech and style serve to achieve an esthetical purpose (Reiss, 2000) [2]. Such texts basically include artistic literary works including literary prose such as essays and biographies; imaginative prose such as short stories, novella s and romances, and poetry in all its forms. Based on that, the prose can be categorized into form-focused text and to produce a high-quality translation of this field, the relevant translation strategies must be followed.

The features of lyric prose are obvious, the writers usually integrate sensibility and rationality, concrete and current life experience, and profound philosophical thinking. On the one hand, some writers have a real and longing perspective on real life, talking about their own experiences, such as childhood life, urban life, men's and women's situations, and so on. Apart from the description of real-life experience, they do a deeper digging of life, meticulously perceive and think about the above-mentioned life phenomenon and cultural phenomenon, and explain their profound insights on life, thus making the proses bring speculation among the readers. In lyric proses, one of the normal artistic methods is materialized images which convey the characters, scenery, or moods exquisitely, delicately, with lovely images, full of artistic charm and exquisiteness. If the translators simply start the translation without analysing the text type, the translation they produce may use the wrong translation strategies, for instance, they may prioritize the accuracy of the information and pay attention to the semantic elements as they aim at maintaining the semantic equivalence in the translation, which is superior to the choice of grammatical and stylistic forms if they define prose wrongly as content-based text.

To be more specific, the author's translation for Eileen Chang's prose can explain the difference. This prose mainly introduces her impressions of people, things, and lives in Shanghai, which belongs to form-focused texts. When translating form-focused texts, the translators need to take the expressive function, the grammatical and stylistic elements of the source text into consideration. Also, some analogous form of expression in the target language should carry the mission of transmitting the artistic form of the source text to achieve a comparable aesthetic effect, which can be shown in the following table.

Table 1:

\begin{tabular}{|c|l|}
\hline Source Text & $\begin{array}{l}\text { “喏, 就是'张勋’的’勋', '功勋”的 ‘勋', 不是'薰 } \\
\text { 风'的'薰'。” }\end{array}$ \\
\hline Target Text & $\begin{array}{l}\text { "Here, it is the 'Xun' of the General 'Zhang Xun' } \\
\text { or of the phrase 'Gong Xun' (merit), not the 'Xun' } \\
\text { of the phrase 'Xun Feng' (fragrant breeze).” }\end{array}$ \\
\hline Back Translation & $\begin{array}{l}\text { 张勋 is a general in China, 功勋 means merit and } \\
\text { 薰风 means a fragrant breeze. }\end{array}$ \\
\hline
\end{tabular}

The original sentence is composed of parallel structures in order to express the character “勋”, which is unique in Chinese. If translating semantically, the sentence could be the "Xun" of "Zhang Xun", the "Xun" of "merit", not the "Xun" of "fragrant breeze". The readers may become confused about the meaning of "Xun", as it does not show in the word "merit" or "fragrant breeze". Thus, to produce high-quality translation, it is better to keep the phrase in the Chinese phonetic alphabet and add further explanation to the phrases. "Xun" is kept in accordance with the source text so the readers are able to comprehend the rhyme. If the translators just define the source text as content-focused text, the semantic elements will become the first focus. The same situation happens in other proses as well. Thus, the quality of translation is closely related to textual features and the corresponding translation strategies.

\section{Cultural Features in High-Quality Translation of Lyric Prose}

Meanwhile, the production of high-quality and convincing translation of lyric prose involves the cultural feature. The translation process can be said to be a process of bilingual conversion, which is a process of expressing the meaning of one language into another language. Most of our translation studies are focused on such translation processes.

When looking at the phenomenon of translation completely, many problems cannot be explained clearly by language alone. From the standpoint of translation history, the following questions are continually put forward by scholars: Why does a culture introduce texts from outside through translation? Who introduced texts from foreign cultures for their own culture? Does the reader of the target language culture trust the translator and the translation? To solve these questions and produce high-quality translation, the translators need to figure out the skopos of their translations. 
When putting the situation in translating lyric proses, the Chinese culture that has lasted for thousands of years is inextricably linked with the time-honored Chinese language. When Chinese is translated into English, not only the carrier of culture is changed, but also the reader's environment of culture no longer exists. The target language has no corresponding words. Moreover, the target audience lacks the knowledge of Chinese cultural background needed to understand the original text, or they use their cultural backgrounds to understand the target text, resulting in misunderstanding. Just as what has been mentioned in the skopos theory, in the translation of lyric proses, the translators aim to let the translations serve the same function as the text of the reader's own native culture. Therefore, translators should be keenly aware of and accurately grasp the target reader's culture, properly supplement the cultural background contained in the source text in the translation, and make necessary clarifications for the concepts easily misunderstood in foreign cultures, so as to help the readers to overcome the cultural barriers.

So when translating lyric proses, as these works have been studied by some foreign writers and scholars, if the translations are inaccurate especially in some aspects associated with cultures, it may greatly influence the understanding of the foreigners as well as cause confusion in the cultural transmission. To better translate the works, translators need to put the context under the target culture and circumstances as shown in the skopos theory to realize the cultural turn. The translation is not the simple transform between two languages, it goes in a special cultural environment.

When translating Eileen Chang's prose, the skopos is to give the readers a relatively comprehensive view of the emotions and life experiences of people in Shanghai. The source text adopts several verses and metaphors to show the life of Shanghainese. For instance, “樽前相对两头牌, 张女云姑一 样佳。塞饱肚皮连赞道: 难受任使踏穿鞋! ” The verses are also in antithesis. However, when putting it under the target text, it may be hard for English speakers to understand the meanings of “头牌” if translating literally into "starring actors", which the readers are not able to understand the intonation. Here, it specifically refers to "Beijing opera singers". To make high-quality translation, the cultural element "Beijing opera" should be added to let the reader better comprehend the situation.

Apart from that, in the previous analyzed sentence, foreigners do not have the person "Zhang Xun" in their cultures and may feel confused about it. He is a general in China, so the supplement knowledge should be affixed to let the readers have a better comprehension, which can be seen from the author's translation in Table 2 .

Table 2:

\begin{tabular}{|l|l|}
\hline Source Text & “喏, 就是'张勋'的'勋'.....” \\
\hline Target Text & $\begin{array}{l}\text { "Here, it is the 'Xun' of the General 'Zhang } \\
\text { Xun'......” }\end{array}$ \\
\hline Back Translation & 张勋 is a general in China. \\
\hline
\end{tabular}

From the above analysis, in lyric proses, the writers are good at using metaphors as well as Chinese slangs, including many cultural elements. According to the skopos theory, the source text should be put under the target circumstance as the translation creates a bridge for cultural communication. Without considering the cultural feature or putting the cultural feature in an important status, the translation will be poor, leading to the result that the readers understanding or analysis will be heavily affected and their perspectives towards our culture may get distorted. In a higher standard, if taking into account the cultural features and produce high-quality translations of proses, the image export of Chinese culture and the establishment of the image of the East could be achieved and intentionally, the characteristics of Chinese culture could be pushed to the Western civilization as translation is like a communicative behavior (Hornby, 1995) [9].

\section{Conclusion}

In conclusion, it is increasingly more significant to produce high-quality translation under the multi-culture society and the circumstance of globalization. As more and more foreign scholars begin to notice the beauty and rich connotation of lyric proses, it is important for the translators to pay attention to the quality of the translations.

Based on Kathria Reiss's text typology theory and skopos theory, the author maintains that the textual and cultural features are crucial in producing high-quality translations of lyric prose, taking the author's own translation for Eileen Chang's “到底是上海人” as an example. To produce highquality translation of proses, the translator need to analyze the text type first to apply relevant translation strategies, focus on the expressive function and the grammatical and stylistic elements of the lyric prose and then put the source text under the target circumstance to realize the cultural turn as highquality translations of Chinese literary works could help promote our philosophy and culture to other countries and make others appreciate the beauty of Chinese literature.

\section{References}

[1] Trosborg, Anna, Text Typology and Translation, John Benjamins Publishing Company, Amsterdam, 1997.

[2] Reiss, Rhodes \& Rhodes, Erroll F., Translation criticism: the potential and limitations, categories and criteria for translation quality assessment, St. Jerome Publishing, Manchester, 2000.

[3] Munday, J., Introducing translation studies: theories and applications, Routledge, London, 2001.

[4] Reiss, Katharina, Vermeer, Hans J \& Nord, Christiane, Towards a General Theory of Translational Action, Taylor \& Francis Group, London, 2014.

[5] Hatim, B. \& Munday, J., Translation: an advanced resource book, Routledge, London, 2004.

[6] Holmes, J.S., The Cross-temporal Factor in Verse Translation, Meta (Montréal), 17(2), pp.102-110, 1972. 
[7] Snell-Hornby, M., Translation studies: an integrated approach, John Benjamins Publishing Company, Amsterdam, 1995.

[8] Bühler, K., Goodwin, D.F. \& Eschbach, A., Theory of language: the representational function of language, John Benjamins Pub. Company, Amsterdam, 2011. 